\title{
A educação a distância em discussão: o curso mídias na educação no Rio Grande do Norte
}

\author{
Distance education in discussion: \\ the media course in education in Rio Grande do Norte
}

\author{
Maria Dalvaci Bento* \\ Arnon Alberto Mascarenhas de Andrade**
}

\begin{abstract}
Resumo: A contemporaneidade nos revela a necessidade de os profissionais, dos mais diversos setores, estarem em constante processo de formação, em especial os professores que devem ser transformados em aprendizes permanentes. Esse fato demonstra que toda profissão tem seu percurso permeado por mudanças, decorrentes do desenvolvimento técnico e científico. A profissão de professor precisa seguir essa mesma lógica. Estar em sintonia com essas mudanças exige dos professores uma preparação sistemática possibilitada pelos cursos de formação continuada. Assim sendo, ressaltamos que a formação continuada de professores é uma consequência do desenvolvimento da sociedade e vem sendo realizada com um percentual significativo por meio da educação a distância. Portanto, neste artigo, faremos uma explanação da implementação do curso Mídias na Educação Extensão no estado do Rio Grande do Norte, desenvolvido pela Universidade do Estado do Rio Grande do Norte (UERN) e Universidade Federal do Rio Grande do Norte (UFRN). Este é um curso a distância, desenvolvido em ambiente virtual de aprendizagem desde 2005.
\end{abstract}

Palavras-chave: EAD. Curso Mídias na educação. Formação continuada.

\begin{abstract}
Contemporary times show the need for professionals from different sectors to take part in continuing formation processes, in particular teachers who should become lifelong learners. This demonstrates that every profession undergoes changes as a consequence of technological and scientific development. The teaching profession needs to follow the same logic, that is, to be aware of these changes and that this requires a systematic preparation through continuing education. Thus, this article highlights that continuing education is a consequence of society's development and that it has been undertaken by a significant percentage of teachers through distant education. This article discusses the implementation of the course Media in Education - Outreach Project - in the state of Rio Grande do Norte, carried out by the University of the State of Rio Grande do Norte (UERN) and by the Federal University of Rio Grande do Norte (UFRN). It is a distance education course developed in a virtual learning environment since 2005.
\end{abstract}

Keywords: Distance education. Media in education. Continuing education.

\footnotetext{
* Doutoranda do Programa de Pós-Graduação em Educação da Universidade Federal do Rio Grande do Norte. E-mail: <dalbebr@yahoo.com.br>.

** Professor do Programa de Pós-Graduação em Educação da Universidade Federal do Rio Grande do Norte. E-mail: <arnon_andrade@uol.com.br>.
} 


\section{Crescimento da educação a distância no Brasil}

O crescimento da educação a distância (EAD) no Brasil tem se dado de forma acelerada, em meados da primeira década do século XXI. Para termos uma ideia de como esse processo vem ocorrendo, de 2004 a 2007 o número de inscritos cresceu $213 \%$ e o de instituições credenciadas $54,8 \%$, segundo o Anuário Brasileiro Estatístico de Educação Aberta e a Distância (AbraEAD) de 2008. Esse número de instituições não foi maior porque algumas estavam aguardando autorização do MEC para poder oferecer seus cursos através da EAD. Somente em 2007, o crescimento do número de alunos matriculados em cursos de EAD credenciados pelo MEC foi de $24,9 \%$ e de instituições credenciadas, $14,2 \%$.

Com base nos dados do Censo da Educação Superior de 2008, divulgado pelo Instituto Nacional de Estudos e Pesquisas Educacionais Anísio Teixeira (INEP), as matrículas em graduações, na modalidade a distância, aumentaram 96,9\% entre 2007 e $2008^{1}$.

De acordo com o Censo EAD.BR de 2009, organizado pela Associação Brasileira de Educação a Distância (ABED), 2,6 milhões de brasileiros se utilizaram da EAD no ano de 2008. Para isso, 1.752 cursos foram ministrados neste mesmo ano por instituições que se utilizam da modalidade a distância. Desses cursos, 31,5\% são voltados para a formação de professores. Esse alto índice nos cursos de formação de professores se deve pelo grande número desses profissionais sem formação adequada para a docência.

Quanto à oferta de cursos, em 2007 foram 299 novos cursos a distância e em

\footnotetext{
${ }^{1}$ Disponível em: <https://www.institutoclaro.org.br/ observatório/reportagens/detalhe/cursos-a-distância> .
}

2008 houve um salto nestes números, pois foram oferecidos 568 novos cursos. Ou seja, em 2008 a oferta de cursos nessa modalidade cresceu $89,9 \%$ em comparação ao ano de 2007. Dessa forma, observamos que em 2008269 novos cursos foram lançados.

Com essa efervescência de cursos de EAD, precisamos observar se estão voltados para a criatividade e a criticidade dos educandos ou se a forma como estão sendo construídos e se apresentam ainda exclui os indivíduos, classifica-os e marginaliza-os. É necessário evitar práticas pedagógicas que incentivem o individualismo e a competição, e que favoreçam a manipulação dos sujeitos, como bem destaca Habermas (1987).

Na opinião de Pretti (2005, p. 33),

O que se percebe é uma grande diversidade de propostas, cujo sentido é responder a problemas específicos. Essa forma de se pensar a EAD tem excluído sistematicamente a ideia de criação de sistemas de EAD em caráter permanente que pudessem atender a projetos e a programas diferenciados, tanto em nível federal como no interior das próprias universidades.

$\mathrm{O}$ autor destaca ainda que o grande problema de algumas propostas em andamento é a indicação de "processos dialógicos e de interação numa perspectiva construtivista” (PRETTI, 2005, p. 34). No entanto, o que se vê, na prática, são a organização desses projetos e suas ações pedagógicas distantes do proposto, sem identidade regional, em que o tutor transfere o que é próprio da sala de aula tradicional presencial para o ambiente virtual do curso.

Não podemos negar que a EAD, na atualidade, tem recebido atenção relevante do governo federal, através do Ministério da Educação (MEC), fato comprovado tanto na formação continuada quanto em cursos de graduação, mas também atingindo a 
pós-graduação nos mais diversos recantos do Brasil, através do Sistema Universidade Aberta do Brasil (UAB). Citamos como exemplo o curso Mídias na Educação ${ }^{2}$ - ao qual daremos ênfase neste artigo -, destinado a professores da rede pública de Educação Básica, voltado para a utilização das linguagens das mídias no processo ensino-aprendizagem, desenvolvido em ambientes virtuais de aprendizagem (AVA). Assim sendo, seus idealizadores entendem que essa formação deve ocorrer mediada pelas tecnologias que servem de suportes para essas mídias e, desta forma, podem conhecer as potencialidades desses suportes que já se fazem presentes em muitas escolas públicas brasileiras.

Nesse sentido, consideramos que o diálogo é fundamental durante todo o processo de oferta do curso, que relacionamos em dois momentos básicos: o primeiro se refere ao momento que antecede o início do curso e, o segundo, durante o período de execução do curso. Considerando essa questão, reportamo-nos a Habermas (1987 apud BONFLEUER, 2001, p. 6) quando este discute a racionalidade instrumental (cognitivo-instrumental ou estratégica) e a racionalidade comunicativa (ação comunicativa), afirmando que na primeira há a evidência de poder subjetivo de um indivíduo sobre o outro, regida pela lógica da dominação:

[...] o ator não vê no companheiro da interação um sujeito com o qual é possível estabelecer um acordo intersubjetivo. Por isso, sua opção será a de agir sobre ele [...].

A segunda, a racionalidade comunicativa, relaciona-se à capacidade dos indivíduos interagirem em grupo, em que seus

${ }^{2} \mathrm{O}$ documento com todo o detalhamento do curso está disponível em: <http://portal.mec.gov.br/seed/arquivos/midias/projetobasico.pdf $>$. interesses são mediados como iguais e coordenam suas ações através do diálogo sincero.

Observamos, portanto, que nestes anos de desenvolvimento do referido curso tem havido uma proliferação na oferta de cursos em EAD. Vale ser ressaltado que a disseminação de cursos nessa modalidade de ensino pode estar relacionada à dinamicidade de uso dos AVA - os quais têm sido utilizados frequentemente. Nessa perspectiva, é necessária muita atenção no sentido de verificar como os participantes dos cursos de EAD estão fazendo uso desse espaço de aprendizagem colaborativa.

\section{A implementação do curso mídias na educação no Rio Grande do Norte}

O curso Mídias na Educação é destinado preferencialmente a professores e gestores da Educação Básica. Ao seu término, é esperado que os professores participantes (os cursistas) tenham adquirido autonomia para criar e produzir, nas diferentes mídias, programas, projetos e conteúdos educacionais; que sejam capazes de refletir a respeito de sua prática, bem como sobre o papel das tecnologias na criação de um novo ambiente educacional; reflitam crítica e criativamente sobre as diferentes linguagens; e sejam capazes de utilizar as diferentes mídias de acordo com a proposta pedagógica que orienta sua prática.

No RN, essa implementação vem se dando por meio da UFRN e da UERN. Cada uma dessas universidades tem se articulado para desenvolver o curso, mas ainda enfrentam alguns problemas que acabam culminando no maior deles: a evasão de muitos cursistas. Não podemos deixar de citar, também, aqueles cursistas que, mesmo se inscrevendo no curso, não participam de nenhuma atividade - os chamados “desistentes”. 
Apesar de receberem da Secretaria de Educação (SEED) o material didático do curso, cada uma pode pensar em como se organizar para oferecê-lo aos professores, considerando apenas o tempo destinado para o curso (não se alongar, além do previsto).

Veremos, a seguir, todo esse processo de implementação e os dados correspondentes ao processo de cada oferta do curso por universidade, em relação ao número de cursistas indicados pelas secretarias de educação, o número dos que se matricularam, dos que concluíram, dos que se evadiram e dos desistentes.

\section{A SEDIS/UFRN e o NEAD/UERN}

A implementação do curso Mídias na Educação pela UFRN é feita através da Secretaria de Educação a Distância (SEDIS) e na UERN pelo Núcleo de Educação a Distância (NEAD).

A UFRN criou a SEDIS em 2003, com o objetivo fomentar a educação na modalidade a distância e estimular o uso das TIC como ferramenta de ensino e aprendizagem. A SEDIS coordena o Programa Universidade a Distância (UNIDIS), que foi criado em 21 de junho de 2005, por meio da Resolução no 033/2005 do Conselho de Ensino, Pesquisa e Extensão (CONSEPE). A UNIDIS possui seis (6) cursos de graduação a distância, sendo seis (6) cursos de licenciatura (Química, Matemática, Física, Biologia, Educação Física e Geografia) e dois bacharelados: Administração e Administração Pública. Atua em 19 polos de apoio distribuídos nos estados do Rio Grande do Norte (Luiz Gomes, Marcelino Vieira, Martins, Mossoró, Macau, Lajes, Extremoz, Guamaré, Natal, Nova Cruz, Currais Novos e Caicó); Paraíba (Campina Grande); Pernambuco
(Tabira, Nazaré da Mata, Recife, Surubim, Garanhuns, Petrolina); e Alagoas (Maceió). Além do mais, ainda oferece cursos de formação latu sensu (especialização). Outros cursos vêm sendo oferecidos pela SEDIS como, por exemplo, o curso de Capacitação de Gestores, E-TEC ${ }^{3}$ Brasil e Mídias na Educação. Nesses cursos, o AVA utilizado tem sido o moodle.

Na UERN, a EAD foi introduzida há pouco mais de uma década, mais precisamente no ano de 1999, quando participou da fundação da UniRede. No entanto, somente em setembro de 2001 foi criado o NEAD.

No mesmo ano de sua fundação, o NEAD ofertou o Programa de Capacitação a Distância para Gestores Escolares (PROGESTÃO), em parceria com a SEEC/RN, curso financiado pelo Conselho Nacional de Secretários de Educação (CONSED). Ainda em 2001 o NEAD iniciou sua participação no curso TV na Escola e os Desafios de Hoje, ofertando a segunda e a terceira edição. Além dessas ofertas, o NEAD se destacou dentro da UERN, no ano de 2003, quando ofereceu o curso de extensão a distância, preparatório para o II Festival de Teatro da UERN (FESTUERN).

E embora o Sistema UAB tenha sido criado em 2005, a UERN - através do NEAD - só passou a integrá-lo no ano de 2009. A incorporação da UERN a esse Sistema oportunizará a expansão de cursos de graduação e pós-graduação (latu sensu) por meio da EAD, na região oeste potiguar, a partir da implantação dos polos de apoio presencial nos municípios de Assu, Caicó, Caraúbas e Macau.

\footnotetext{
${ }^{3}$ Disponível em: <http://etecbrasil.mec.gov.br>.
} 


\section{Articulações necessárias para a execução do curso mídias na educação}

Inicialmente, para participar da implementação desse curso, tanto as universidades - UERN e UFRN - como a Secretaria de Estado da Educação e da Cultura do Rio Grande do Norte (SEEC) e a União dos Dirigentes Municipais de Educação (UNDIME/ RN) assinaram um Termo de Compromisso, o que confere adesão à oferta do curso. Nesse "termo" constam as responsabilidades de cada instituição na implementação do curso. Tais instituições indicam os coordenadores responsáveis.

A distribuição de vagas dá-se em reunião (a primeira) com os coordenadores nomeados: coordenador geral e de tutoria das universidades, coordenador da Secretaria de Educação e coordenador da UNDIME/RN. A divulgação do curso e as inscrições, por sua vez, são realizadas pela SEEC e UNDIME/RN. A SEEC envia ofício circular às dezesseis (16) Diretorias Regionais de Educação (DIRED) do RN com informações sobre o curso, como seu objetivo, perfil dos cursistas, número de vagas e planilha de inscrição, além de uma ficha para preenchimento de dados completos. As DIRED, em cada oferta, selecionam algumas escolas a serem atendidas, já que, muitas vezes, a demanda é maior do que a oferta. No processo de inscrição, algumas DIRED levam em conta as escolas que não participaram de ofertas anteriores do curso; outras não estabelecem nenhum critério. Um técnico-pedagógico da DIRED se encarrega de realizar as inscrições e normalmente faz isso por telefone ou em contato com os gestores escolares, quando estes vêm à DIRED. A UNDIME/RN vem realizando suas inscrições através dos dinamizadores municipais - existentes em cada secretaria municipal -, que respondem pelos
Programas TV Escola, Proinfo e, também, pelo curso Mídias na Educação. Assim, a UNDIME/RN envia ofício às secretarias municipais de educação com as mesmas orientações feitas pela Secretaria Estadual de Educação, porém não segue um critério, chegando até a ocorrer inscrições sem que o cursista tenha conhecimento do curso, tão pouco do próprio processo de inscrição.

Reconhecemos que o processo adotado pelas DIRED e secretarias municipais de educação prejudica os professores que realmente têm interesse em participar do curso, porém não têm conhecimento do processo de inscrição. Acreditamos que deveria haver um processo seletivo para os professores interessados poderem participar, sem privilegiar uns e outros.

Após as inscrições serem realizadas pelas DIRED e secretarias municipais de educação, são enviadas a SEED em nome do coordenador nacional do curso e este, por último, direciona-as para as duas IPES, responsáveis pela execução do curso no estado do Rio Grande do Norte.

Numa segunda reunião, os coordenadores definem a distribuição de cursistas por proximidade de município de cada universidade. Também, são previstas as datas dos encontros presenciais, tendo em vista o início do curso, bem como o local para realização desses encontros. Normalmente, as duas IPES realizam seus encontros presenciais em datas diferentes, principalmente, por causa dos espaços físicos para isso.

Essas duas universidades utilizam plataformas virtuais diferentes para hospedarem o curso: a UERN, o e-proinfo e a UFRN, o moodle.. 


\section{Participação da ufrn no curso mídias na educação}

A UFRN, por meio da SEDIS, participa do curso Mídias na Educação, desde o princípio, tanto na elaboração de conteúdo do módulo Material Impresso quanto na implementação do curso. Assim, até 2009, a UFRN participou do projeto-piloto (2005), da segunda (2007/2008) e da terceira oferta (2008/2009) do Ciclo Básico. Portanto, não participou da primeira oferta do referido ciclo e de nenhuma oferta do Ciclo Intermediário e do Avançado. No primeiro caso, o motivo da não participação se deveu ao fato da equipe de professores da SEDIS envolvida com o curso ser bastante reduzida (três professores) e por estarem produzindo conteúdo para o Módulo Material Impresso. No segundo caso, a equipe optou por não ofertar o Ciclo Intermediário, deixando claro que seus módulos seriam incorporados ao Ciclo Avançado. Este, por sua vez, seria ofertado em 2010, mas devido ao processo de tramitação do curso para a CAPES, a UFRN optou por não mais oferecer o referido ciclo.

Quando o curso foi lançado em 2005, a UFRN foi responsável pela execução do projeto-piloto no Rio Grande do Norte. Assim, para participar dessa fase inicial do curso, a SEEC inscreveu 20 professores com experiência na utilização das TIC na educação, como multiplicadores dos NTE e coordenadores do Programa TV Escola e Proinfo. Destes, apenas um inscrito não participou do projeto. Este projeto-piloto era constituído apenas pelo Módulo Introdutório (Integração de Mídias) e, na época, a UFRN utilizou o ambiente virtual e-proinfo. Um dado relevante é que houve apenas uma desistência e nenhuma evasão. É possível que isso se deva a dois fatores: a) o fato de ser apenas um módulo, com carga horária pequena (30 horas); b) todos os participantes tinham experiência com tecnologias na educação.

Os participantes receberam certificação de curso de Extensão pela participação nesse projeto-piloto.

Na segunda oferta do curso que ocorreu parte em 2007 (A UFRN não participou da primeira oferta nacional) e outra parte em 2008, os participantes do curso foram todos professores da rede municipal de ensino, sendo a maioria de Natal.

A seguir, apresentamos os dados referentes a essa oferta, porém queremos enfatizar que esses dados (e os dos demais quadros) foram extraídos do Sistema de Gestão Questionário de Avaliação (SGQA) ${ }^{4}$ sistema de armazenamento dos dados gerais do curso Mídias na Educação, informados pelas Instituições Públicas de Ensino Superior (IPES) ofertantes. Ao final de cada ciclo ofertado, os tutores enviam relatórios à coordenação de tutoria informando a respeito do desenvolvimento do curso em suas turmas. Essa coordenação faz um relatório geral no referido sistema. Assim, os dados gerais dessa oferta estão organizados da seguinte forma:

Quadro 1: Ofertas do Ciclo Básico (UFRN)

\begin{tabular}{|c|c|c|}
\hline Descrição & \begin{tabular}{|l|}
$2^{\mathrm{a}}$ oferta do \\
Ciclo Básico
\end{tabular} & \begin{tabular}{|l|}
$3^{\mathrm{a}}$ oferta do \\
Ciclo Básico
\end{tabular} \\
\hline $\begin{array}{l}\text { Cursistas indicados pela Secretaria } \\
\text { de Educação }\end{array}$ & 100 & 543 \\
\hline $\begin{array}{l}\text { Cursistas matriculados no Ciclo } \\
\text { Básico }\end{array}$ & 100 & 543 \\
\hline $\begin{array}{l}\text { Cursistas que concluíram Ciclo } \\
\text { Básico }\end{array}$ & 46 & 202 \\
\hline $\begin{array}{l}\text { Cursistas desistentes (nunca } \\
\text { acessaram o ambiente) }\end{array}$ & 16 & 141 \\
\hline Cursistas evadidos & 38 & 200 \\
\hline
\end{tabular}

Fonte: Sistema de Gestão Questionário de Avaliação (SGQA)

${ }^{4}$ Disponível em: <http://sgqaadm.mec.gov.br>. 
Pelos dados expostos, identificamos que a UFRN não teve problemas para matricular os cursistas, já que todos os indicados pela UNDIME/RN foram inscritos na plataforma moodle do curso. Podemos constatar que dos cursistas inscritos na segunda oferta do Ciclo Básico, 46\% concluíram o curso, 16\% desistiram do curso (não fizeram nenhum acesso) e $38 \%$ se evadiram. Depreendemos então que o número de desistentes e evadidos superou o número de concluintes, ou seja, teve um total de $54 \%$. Já a evasão foi maior do que a desistência - 22\%.

Logo após o término da segunda oferta do Ciclo Básico do curso, houve a terceira oferta, compreendendo o período do final de 2008 e praticamente metade de 2009 . Nessa oferta, os participantes foram professores tanto da rede estadual quanto da rede municipal de educação. Os dados mostram que o problema de desistência e de evasão continua bastante acentuado.

Assim, da mesma forma que na oferta anterior, todos os cursistas indicados pela SEEC e pela UNDIME/RN foram inscritos na plataforma moodle. Dos inscritos, apenas 37,2\% concluíram o curso. E, assim, 25,9\% nem ao menos compareceram ao encontro presencial de abertura do curso - correspondendo àqueles considerados desistentes do curso - e $36,8 \%$ se evadiram no decorrer do processo. Sendo assim, a diferença daqueles que se inscreveram no curso, mas não o concluíram, foi de $62,7 \%$.

Enfatizamos, aqui, que a UFRN, em 2010, não ofertou o curso e no biênio 2010/2011 ofertará o curso de Especialização em Mídias na
Educação - nova nomenclatura adotada com a migração do curso para a Coordenação de Aperfeiçoamento de Pessoal de Ensino Superior (CAPES) -, ou seja, o curso sem a estrutura curricular em ciclos, considerando as definições propostas na mudança do curso da SEED para a CAPES.

\section{Participação da uern no curso mídias na educação}

A UERN, através do NEAD, vem participando do curso tanto na elaboração de material didático quanto na implementação do curso, exceção feita ao projeto-piloto que foi responsabilidade apenas da UFRN. Na elaboração de material didático, a UERN contribuiu na produção de conteúdo do Módulo Informática. Já na implementação do curso Mídias na Educação, até o ano de 2009 participou da primeira (2006/2007), segunda (2007/2008) e terceira oferta (2008/2009) do Ciclo Básico e da primeira (2008) e segunda oferta (2009) do Ciclo Intermediário. O Ciclo Avançado, durante o período de 2005 a 2009, não foi ofertado por esta universidade.

Vejamos, a seguir, a descrição dos dados correspondentes à oferta do Curso Mídias na Educação pela UERN:

Quadro 2: oferta do Ciclo Básico e do Ciclo Intermediário (UERN)

\begin{tabular}{|l|c|c|c|c|c|}
\hline Descrição & $\begin{array}{l}1^{\circ} \text { ciclo } \\
\text { - Básico }\end{array}$ & $\begin{array}{l}2^{\circ} \text { ciclo } \\
\text { - Básico }\end{array}$ & $\begin{array}{l}3^{\circ} \text { ciclo } \\
\text { - Básico }\end{array}$ & $\begin{array}{l}1^{\circ} \text { ciclo - } \\
\text { Intermediário }\end{array}$ & $\begin{array}{l}2^{\circ} \text { ciclo - } \\
\text { Intermediário }\end{array}$ \\
\hline $\begin{array}{l}\text { Cursistas indicados pela } \\
\text { Secretaria de Educação }\end{array}$ & 97 & 400 & 566 & 35 & 169 \\
\hline Cursistas matriculados & 97 & 400 & 459 & 35 & 169 \\
\hline Cursistas que concluíram & 35 & 176 & 183 & 27 & 135 \\
\hline $\begin{array}{l}\text { Cursistas desistentes } \\
\text { (nunca acessaram o } \\
\text { ambiente) }\end{array}$ & 27 & 0 & 0 & 0 & 0 \\
\hline Cursistas evadidos & 35 & 224 & 276 & 08 & 34 \\
\hline
\end{tabular}

Fonte: Sistema de Gestão Questionário de Avaliação (SGQA) 
Nessa primeira oferta do curso, foram inscritos somente professores da rede estadual de ensino, indicados pela SEEC. Pelo exposto, vemos que a UERN conseguiu inserir na plataforma e-proinfo do curso todos os cursistas indicados pela SEEC. No entanto, somente $36 \%$ concluíram o curso; $27,8 \%$ desistiram; e $36 \%$ se evadiram. Mais uma vez, os evadidos foram em maior quantidade do que os desistentes. Assim, o número de cursistas que não concluíram fica em torno de 63,8\%, um número bem alto. Embora o número de inscritos tenha sido bastante pequeno, a evasão foi muito acentuada, o que deve ter gerado certa preocupação à universidade.

Na segunda oferta do Ciclo Básico do curso, os participantes foram professores da rede estadual e municipal de ensino indicados pela SEEC e UNDIME/RN.

Conforme ocorreu na primeira oferta do Ciclo Básico, os cursistas indicados pela SEEC e UNDIME/RN foram todos matriculados no e-proinfo. Desses, apenas, $44 \%$ concluíram o Ciclo e $56 \%$ se evadiram durante o desenvolvimento do curso. Como vemos, todos os inscritos compareceram ao encontro de abertura do curso, já que não houve nenhum desistente. Mais uma vez, a evasão prevaleceu sobre os que concluíram o curso.

$\mathrm{Na}$ terceira oferta, também, participaram professores tanto da rede estadual quanto da rede municipal de ensino. Observamos que nem todos os cursistas indicados pela SEEC e UNDIME foram inscritos na plataforma e-proinfo, ou seja, sete (7) deles não foram inscritos. Normalmente, isso acontece quando os dados necessários para o cadastro do cursista na plataforma do curso estão errados e a UERN, SEEC ou UNDIME/RN não conseguem manter contato com os cursistas para fazer a correção. Ou, ainda, quando conseguem o contato, há cursistas que informam não desejarem mais participar do curso. Assim, nesta oferta, dos cursistas cadastrados, somente 39,8\% concluíram o Ciclo Básico. No entanto $60 \%$ se evadiram no decorrer do curso. Conforme a tabela acima, também, não houve desistência.

Já na primeira oferta do Ciclo Intermediário, os cursistas vêm da primeira oferta do Ciclo Básico, por isso confirmam sua inscrição no encontro de encerramento deste. Todos os indicados foram inscritos e destes $77 \%$ concluíram o Ciclo; os evadidos foram 22,8\% e não houve desistentes. Como podemos observar, neste ciclo os dados se invertem em relação ao Ciclo Básico, ou seja, o número de cursistas que concluíram é bem maior do que os que se evadiram, sendo basicamente esta diferença em torno de 57\%. Parece-nos que, à proporção que o cursista vai se envolvendo com o curso, que já está familiarizado com a metodologia, consegue se organizar melhor para os estudos a distância.

Na segunda oferta do Ciclo Intermediário, os participantes desta oferta são os que concluíram a segunda oferta do Ciclo Básico. Mais uma vez, todos os cursistas indicados pela SEEC e UNDIME/RN foram inscritos na plataforma do curso. Desse total, 79,8\% concluíram o ciclo; apenas $20 \%$ se evadiram; e nenhum deles desistiu. Mais uma vez, constatamos que o número de cursistas que concluíram foi bem maior do que daqueles que se evadiram. Consideramos necessário, no resultado de cada oferta do curso, indicar os cursistas que concluíram e os cursistas que não concluíram o curso (e aqui entraria o somatório dos desistentes e dos evadidos).

Ao terminarmos a descrição desses dados, queremos destacar que, em 2010, a UERN esteve na quarta oferta do Ciclo Básico, ainda nos moldes do curso por ciclo, oferecendo 500 vagas, e na terceira oferta do Ciclo Intermediário, com 244 vagas. Como vemos, esta universidade ainda não está participando do novo formato do curso, 
conforme definido no processo migratório do curso da SEED para a CAPES, devido ao fato de já ter definido, junto ao FNDE, no momento dos acertos para a referida migração, os recursos financeiros para a quarta oferta do Ciclo Básico e a terceira do Ciclo Intermediário.

\section{A tutoria: seleção, capacitação e acompanhamento}

A tutoria é um dos aspectos relevantes de um curso a distância. Por isso, o processo de seleção, capacitação e acompanhamento dos tutores deve ser bastante criterioso. Segundo Palloff e Pratt (2004), uma das principais críticas relacionadas à aprendizagem em cursos on-line é a ausência de interação pessoal. Para os autores, a presença do professor (tutor) é fundamental na condução dos fóruns de discussão, no envio de e-mails, respondendo às atividades enviadas, e, mais do que isto, quando o tutor dá exemplo de boa interação e comunicação isto se refletirá no desempenho dos alunos.

Com essa preocupação destacamos que, para a realização do processo de seleção dos tutores, bem como a capacitação e o acompanhamento de sua atuação durante o desenvolvimento de cada oferta do curso, as duas universidades adotam algumas estratégias semelhantes, porém outras são diferentes. Essa situação é possível porque as universidades têm autonomia para decidir como deve ser realizado todo o processo. Vejamos, a seguir, como age cada universidade.

A UFRN, na segunda oferta do Ciclo Básico (2007/2008) do curso (mas primeira oferta pela UFRN), utilizou dois tutores e, para isto, foram indicados dois professores da própria SEDIS. Já na terceira oferta do Ciclo Básico (2008/2009), foram necessários 10 tutores, sendo escolhidos oito professores-multiplicadores de NTE e dois mestrandos, organizados em dois grupos: um desses grupos estava concentrado em Natal e o outro em Caicó. A UFRN não fez seleção de tutores por edital. Nessa seleção, foi levada em conta também a experiência que esses profissionais têm com a utilização das TIC na educação.

A capacitação de tutores é feita presencialmente durante dois dias. Nesta capacitação é dada ênfase nas funções do tutor, mas também é feito um treinamento na utilização do AVA do curso (moodle).

O acompanhamento do trabalho do tutor é realizado através do próprio ambiente do curso, verificando sua participação, seus comentários nas atividades dos alunos e também por comunicações via e-mail. Além disso, acontecem reuniões periódicas da coordenação de tutoria com os tutores, principalmente quando ocorrem problemas no decorrer da execução do curso. Os tutores emitem, ainda, relatórios parciais sobre o andamento do curso, a cada módulo, bem como ao final, e enviam à coordenação de tutoria.

Na UERN, inicialmente, as ações voltadas para tutoria não têm sido diferentes da UFRN, como, por exemplo, o processo de seleção de tutores. Na primeira oferta do Ciclo Básico, foram indicados dois professores da própria universidade para a função de tutor. Da mesma forma, aconteceu na segunda oferta do Ciclo Básico (e primeira do Ciclo Intermediário), ou seja, foram indicados quatro professores-multiplicadores de NTE para o Básico e um para o Intermediário. Porém, na terceira oferta do Ciclo Básico e segunda do Intermediário, a UERN fez a seleção de tutores por meio de edital, disponibilizado no seu site, no link do NEAD. Assim, foram selecionados 10 tutores para o Ciclo Básico e três para o Intermediário. 
No que se refere à capacitação dos tutores, na primeira e segunda oferta do Ciclo Básico e primeira do Intermediário a capacitação se deu por meio de um Curso de Tutoria disponibilizado no ambiente e-proinfo. Os tutores também foram treinados no uso do ambiente do curso (e-proinfo).

A partir da terceira oferta do Ciclo Básico (e segunda do Intermediário), a capacitação vem se dando da seguinte forma: a UERN envia aos tutores textos relacionados à tutoria para uma leitura prévia e, em seguida, realiza um encontro de oito horas de atividades para discussão dessas leituras e exposição de informações sobre o desenvolvimento do curso. Nesse encontro, há também orientações sobre a navegação no ambiente $e$-proinfo para os tutores iniciantes.

Para o acompanhamento das atividades do tutor, as estratégias adotadas pela UERN são semelhantes às da UFRN, uma vez que estas seguem as orientações gerais estabelecidas no projeto pedagógico do curso, porém a UERN utiliza outro recurso da comunicação: o telefone. Esse recurso é utilizado, principalmente, quando há problemas com os cursistas, como, por exemplo, a ausência de alguns deles por muitos dias.

\section{Os encontros presenciais}

Para abertura e encerramento do curso, acontecem encontros presenciais em lugares específicos, definidos entre as duas IPES, a SEEC e a UNDIME, constituindo-se polos de encontros.

Os polos da UFRN, neste curso, concentram-se nos municípios de Caicó e Natal e os da UERN nos municípios de Mossoró e também em Natal. Essa distribuição é feita considerando, principalmente, a disponibilidade de laboratórios de informática conectados à
Internet banda larga para a realização do encontro presencial inicial. Essa realidade será diferente com a mudança do curso para a CAPES, uma vez que esses encontros serão realizados nos polos da UAB das duas IPES citadas, existentes no estado do Rio Grande do Norte.

Assim, para o encontro presencial inicial, as universidades enviam convites, via e-mail, para que os professores inscritos no curso participem, em local e data previamente agendada. No primeiro momento desse encontro, os cursistas e tutores têm a oportunidade de se conhecer pessoalmente, embora o ambiente virtual do curso disponibilize espaços para fotos dos inscritos e descrição do perfil de cada um. Há, também, uma exposição, por parte do tutor, sobre o curso - quando todo o encontro é realizado por tutores em cada turma -, ou pelo coordenador de tutoria. No segundo momento do encontro, os tutores orientam os cursistas na navegação pelo ambiente virtual do curso. Nesse momento, a UERN tem mais dificuldades, porque o e-proinfo sempre apresenta problemas: tempo de login curto; às vezes, a Internet do laboratório de informática não favorece seu acesso; e outras vezes a página do site fica indisponível (o ambiente moodle da UFRN não enfrenta esse tipo de problema).

Para muitos cursistas, esse encontro se constitui num dilema, pois estes não dispõem de conhecimentos básicos em informática e saem do encontro sem saber navegar pelo curso. Aqueles inscritos que realmente estão motivados para fazer o curso, mesmo com dificuldades, permanecem, quando têm apoio efetivo do tutor. Porém, quando isso não acontece, são potenciais evadidos. Uma atitude a ser tomada no encontro presencial inicial e que poderia minimizar esse problema é o que propõe Palloff e Pratt (2004, p. 90): 


\begin{abstract}
Mostrar aos alunos on-line qual é sua responsabilidade no curso e quais são as expectativas que se têm deles para ajudá-los a entender o que é a aprendizagem on-line antes de continuar o curso, eliminando, assim, surpresas.
\end{abstract}

Os autores defendem que essa atitude poderia levar os alunos a continuar no curso até seu final. Para isso, seria necessária a atuação atenta do tutor, apoiando os cursistas, tirando suas dúvidas, auxiliando constantemente no processo de aprendizagem.

No encontro presencial de encerramento, num primeiro momento, há uma seção de painéis com a exposição dos resumos dos trabalhos finais do ciclo (em forma de banner). Em seguida, cada grupo de trabalho (o trabalho final é feito em equipe), faz uma exposição geral do seu trabalho (às vezes, já em desenvolvimento). Esse pode ser considerado o ápice do encontro, pois é o momento em que os participantes discutem sobre cada trabalho apresentado, fazendo questionamentos e apresentando sugestões. No último momento do encontro é realizada a avaliação do curso, do tutor e uma autoavaliação do cursista.

Esses dois encontros presenciais diferem não somente no tipo de atividades realizadas, mas também na participação dos cursistas. No primeiro encontro, esses professores demonstram curiosidade em relação ao curso, mostram-se atentos em relação à apresentação do curso, bem como às orientações de navegação pelo ambiente virtual. Porém, ocorre menos diálogo. No encontro final, há uma multiplicidade de diálogos, uma vez que querem partilhar, uns com os outros, sua trajetória no curso, as dificuldades enfrentadas, as descobertas feitas, as mudanças que vêm empreendendo na prática pedagógica. Quando cada grupo vai apresentar o trabalho final, há um interesse recíproco, em que questionamentos são levantados e curiosidades são sanadas. Isso acontece tanto com os cursistas da UFRN quanto com os da UERN.

No entanto, a realização desses encontros tem trazido algumas preocupações para as duas IPES, a SEEC e a UNDIME/ RN. O primeiro aspecto preocupante diz respeito à realização do encontro presencial de abertura do curso, já que é necessário disponibilizar espaço físico com computadores conectados à Internet, porém os laboratórios não dispõem de computadores suficientes para atender uma turma de 50 cursistas, por exemplo, mesmo colocando dois deles usando um computador. Outro aspecto que dificulta a participação nos encontros presenciais é o fato de muitos cursistas terem que se deslocar para as cidades-polo do curso e parte deles tem problemas com relação a pagamento de diárias pelos órgãos competentes - SEEC e UNDIME.

Com a transferência do curso para a CAPES, esses encontros serão realizados nos polos da UAB e, sendo assim, há uma perspectiva de que os problemas possam ser minimizados, já que tanto a UFRN quanto a UERN possuem polos da UAB distribuídos em alguns municípios do estado (o deslocamento só é pago de um município para outro).

\section{Dificuldades para a execução do curso}

Na realização desse curso, as duas universidades - UFRN e UERN - vêm enfrentando algumas dificuldades. Inicialmente, essas dificuldades se relacionam ao processo de divulgação do curso e de infraestrutura. Para realizar o cadastramento dos professores na plataforma do curso, a coordenação de tutoria tem dificuldade devido a erros de dados na ficha de inscrição enviada por eles. 
Há o problema daqueles professores que se inscrevem no curso, mas não se informam sobre o que se trata e outros que se inscrevem em dois ou mais cursos, ao mesmo tempo, e não dão conta de realizar os estudos e atividades; e há, ainda, aqueles que se inscrevem, mas, no entanto, quase não acessam o e-mail e assim não têm acesso às informações. Acreditamos que essas contingências sejam reflexo de problemas na gestão de políticas de formação continuada, tanto na rede estadual como na rede municipal de ensino do Rio Grande do Norte.

É verdade que muitos cursistas têm dificuldades de acessar o ambiente virtual do curso porque dispõem de poucos conhecimentos em informática. Dessa forma, por mais que sejam orientados, têm dificuldades em utilizar as ferramentas para leitura do conteúdo, postagem das atividades, acesso à agenda das atividades, ferramenta de contato com tutor e os colegas de turma, entre outros.

Além de tudo isso, em muitos municípios do estado do Rio Grande do Norte, há sérios problemas na conexão de Internet, como, por exemplo, o tipo de conexão que não permite baixar arquivos e programas. No período de chuvas, também, o acesso à Internet, em muitos municípios, fica comprometido. Nesses casos, a alternativa para os cursistas vem sendo a utilização de CD com o conteúdo e atividades do curso. Assim, só acessam o curso on-line para a postagem das atividades. No entanto, às vezes exige deslocamento para o município vizinho. Esse tem sido um problema sério, mas mesmo assim o governo estadual e os municipais não têm apresentado uma solução plausível. Além do mais, depois que o MEC iniciou o processo de distribuição de Internet banda larga nas escolas públicas, os citados governos se eximem de suas responsabilidades nesse aspecto. O problema é que a instalação da Internet banda larga é gradativa e, assim, em muitos municípios são penalizados pela demora.
Outro aspecto que tem atrapalhado o desenvolvimento do curso diz respeito ao fato de iniciar uma oferta quase ao final do ano letivo (final do mês de outubro, por exemplo), conforme ocorreu com a segunda e a terceira oferta do Ciclo Básico. Como é o primeiro módulo do curso e, para a maioria dos cursistas, é também o primeiro curso realizado na modalidade a distância (mais ainda, em AVA), é preciso tempo para conhecer o ambiente virtual, aprender a utilizar realmente as ferramentas do ambiente, bem como se acostumar a gerenciar seus horários de estudos. Porém, parte do estudo do primeiro módulo vai coincidir com a realização das provas das escolas da rede estadual e municipal de ensino. Isso significa que o professor fica sobrecarregado de trabalho, ocasionando atrasos na postagem das atividades do curso e, em muitas vezes, sem tempo para fazê-las. Relacionado a isso, outra dificuldade presente é o fato das atividades do curso de um ano para outro retornarem no início de fevereiro. Nesse período, os cursistas ainda estão no período de férias. Isso poderia não se constituir um problema, se todos os professores tivessem computador em suas residências, porém isso não é realidade. Sendo assim, muitos necessitam acessar os laboratórios de informática das escolas, que, no entanto, se encontram fechados por ocasião das férias escolares. Dessa forma, pareceu-nos que, no planejamento para a execução do curso, não foram levadas em conta essas questões.

Gostaríamos de enfatizar, aqui, que a formação continuada de professores, na modalidade a distância, deve ser em serviço, preferencialmente. Porém, não é isso o que tem ocorrido com o curso Mídias na Educação, uma vez que o tempo do professor não foi levado em consideração, ao elaborar essa formação docente. $O$ fato de o curso ser ofertado na modalidade a distância não significa 
que não devam ser contempladas horas para os estudos na carga horária do professor. Esse é um sério complicador, pois o professor acaba sendo penalizado, uma vez que não disponibiliza de tempo para os estudos e, em consequência disto, muitos se evadem.

Palloff e Pratt (2004, p. 153) afirmam que é preciso considerar o que o aluno quer $\mathrm{e}$ precisa num curso a distância on-line:

[...] comunicação e feedback, interatividade e sentido de comunidade, direção adequada e capacitação para executar as tarefas exigidas. Se copiarmos o que acontece na sala de aula presencial, não atenderemos essas necessidades, causando angústia e frustração aos alunos.

A preocupação dos autores é pertinente, porém não temos identificado que as instituições que elaboram os cursos tenham uma preocupação maior em relação ao que os alunos querem (dos cursos). Salientamos que no Rio Grande do Norte as duas universidades têm apontado a evasão como um dos fatores preocupantes, mesmo com as possibilidades de interação que as novas TIC - computador, Internet, software, ambientes virtuais de aprendizagem - oferecem na contemporaneidade. A constatação do índice de evasão nesse curso contrasta com a necessidade de formação contínua do profissional da educação e isto se revela uma realidade e uma preocupação.

\section{A evasão: como as duas ipes vêm lidando com isto?}

A UFRN e a UERN sempre se empenharam em reduzir o número de cursistas que se evadem e, para tanto, vêm tomando algumas medidas para que essa situação seja minimizada. Uma dessas iniciativas utilizadas para retorno dos cursistas ausentes tem sido o envio de mensagens eletrônicas ou contato por telefone para identificar o motivo da ausência no curso, mas também fazer o convite para seu retorno. A maioria dos ausentes não retorna ao curso, alegando motivos diversos, já citados anteriormente (quando nos referimos às dificuldades).

Uma segunda iniciativa das universidades é estipular novos prazos de entrega de atividades para esses cursistas que retornaram ao curso. Dessa forma, há um reordenamento das datas de entrega das atividades, porém estas são realizadas concomitantemente com a do módulo atual.

Uma terceira iniciativa diz respeito ao incentivo à formação de grupos de estudos, por escola ou por município. Em muitas escolas, há mais de um professor fazendo o curso; assim, há a possibilidade de formação de grupos por escolas. Acontece o mesmo nos municípios menores do estado em que há professores de diferentes escolas, mas que podem formar um só grupo, pela proximidade que há em cidades muito pequenas. Quando há essa formação de grupos, os professores conseguem se envolver mais com o curso, realizando as atividades propostas, trocando ideias, sugestões e depois publicando no ambiente do curso. Isso ocorre, muitas vezes, por causa das vivências dos professores com a educação presencial, o contato face a face, o diálogo.

Uma quarta iniciativa adotada pelas duas universidades se refere ao redirecionamento de algumas atividades: para que os cursistas possam realizar as atividades em menos tempo, é feita a junção de atividades afins em uma só, sem comprometer o objetivo a que se propõem as atividades fundidas. Esse é um trabalho feito pelo coordenador de tutoria em parceria com os tutores. 
Outra iniciativa que tem ganhado força é um encontro que acontece com a coordenação de tutoria e tutores no sentido de discutir as causas de evasão e buscar soluções. Além disso, trocam informações, compartilham soluções e planejam superar impasses. Porém, salientamos que essas estratégias nem sempre têm dado certo para resgatar os cursistas ausentes, pois uma vez que estes se atrasaram no curso, normalmente falta interesse em retornar, como, por exemplo, nos casos de ausência por motivos de saúde. Por outro lado, há aqueles que embora se ausentem do curso justificam sua ausência quando procurados pela tutoria, demonstrando interesse em retornar ao curso. Nesse caso, pressupõe-se que o tutor deva, neste momento, apresentar outros caminhos para a manutenção do cursista, considerando suas dificuldades, mas também defendendo a sua permanência. Acreditamos que situações assim se resolvem por meio do estabelecimento de um diálogo dessa natureza, crítico e, como tal, capaz de modificar a realidade apresentada - perspectiva freiriana -, e que, portanto, qualquer programa de formação continuada a distância deve levar tais contingências em consideração, quando pensar em seu êxito. Assim, no decorrer da implementação do curso, o grande instrumento utilizado tanto pela coordenação de tutoria quanto pelos tutores para trazer os ausentes de volta é exatamente o diálogo. Sua falta, portanto, em todos os momentos que envolvem tal implementação é um agravante e como consequência poderemos ter a desistência e a evasão de muitos cursitas. Por isso, compreendemos que nos cursos de formação continuada a distância deve ser evidenciada a ação comunicativa proposta por Habermas, por meio da relação dialógica, que possibilite a crítica na realidade que se quer transformar, sendo assim uma relação entre iguais, que a partir do seu cotidiano constrói uma visão crítica do mundo e alcança um consenso.

Enfatizamos que tanto Freire (2010) como Habermas (1987) defendem que o diálogo é fundamental tanto para amadurecer as ideias quanto para fazer negociações e chegar a um consenso. Diante das dificuldades enfrentadas na execução do curso, o caminho indicado por esses autores pode ser o melhor a ser seguido.

\section{Um olhar positivo}

Embora exista o problema de evasão no curso Mídias na Educação, parte dos cursistas que o realizam dedica-se a cumprir o cronograma estabelecido no tempo determinado, enquanto outra parte atrasa a postagem das atividades.

Desses cursistas que permanecem no curso, alguns se enquadram entre aqueles com dificuldades relacionadas aos conhecimentos básicos em informática, porém conseguiram superar essas dificuldades, alguns até chegando a participar de minicurso para diminuir sua deficiência no manuseio da ferramenta. Há aqueles que mesmo não disponibilizando de computador conectado à Internet em suas residências, muitas vezes utilizando-se de lan house, envolvem-se com o curso e conseguem cumprir o cronograma previsto para cada módulo.

Através da realização das atividades, o curso permite que os cursistas possam relatar experiências vivenciadas em sua prática pedagógica e partilhar com toda a turma. Embora considerando necessária atenção para o fato de que o excesso de atividades de fórum numa mesma etapa do curso possa torná-lo cansativo, este ainda é o espaço virtual 
do curso onde percebemos que há maior troca entre os cursistas. Isso tem sido identificado quando acessamos as turmas tanto da UFRN quanto da UERN e constatamos a intensa participação dos cursistas nos fóruns, assim como seu envolvimento para aprofundar a discussão. Dessa forma, o fórum tem se constituído um espaço onde há maior interação entre cursistas e cursistas; cursistas e tutores.

A partilha de experiências se estende fora do ambiente do curso, quando os professores passam a compartilhar projetos de trabalho desenvolvidos, via e-mails, e depois os adaptam à realidade de suas escolas. As atividades servem, também, de espaços para as denúncias dos professores quando a sala da TV Escola e o laboratório de informática de determinadas escolas não funcionam. Esses problemas denunciados se evidenciam através da falta de manutenção dos equipamentos tecnológicos, salas de TV Escola e dos laboratórios de informática fechados por não disporem de um profissional responsável (justificativa de alguns gestores), computadores encaixotados por falta de instalação, entre outros. Dessa forma, as escolas devem ter, no mínimo, uma infraestrutura que dê conta do funcionamento das tecnologias.

\section{Considerações finais}

Com a formação continuada, os professores têm a oportunidade de redimensionar sua prática a partir dos novos estudos, da troca de experiência com os outros participantes e da construção de novos conhecimentos. Somos conscientes de que somente a formação inicial não dá conta de preparar o professor para o exercício da docência. A formação continuada é extremamente importante por possibilitar ao professor a reconstrução de seus saberes docentes.

Ressaltamos que a expansão e consolidação da formação continuada passam a se dar através dos AVA, ao passo que esses ambientes estão construídos e são reconstruídos. Por outro lado, é necessário admitirmos que deve haver uma mudança metodológica em relação aos cursos de formação continuada oferecidos em outros ambientes, como os cursos em que eram utilizados somente material impresso enviado via Correios ou aqueles através da TV, auxiliados por material impresso, os quais antecede a disseminação dos cursos em AVA. Assim, é preciso considerar tanto os aspectos estruturais do curso quanto o perfil dos cursistas, principalmente quando é a primeira vez que estão participando de um curso nesses moldes. Fazemos essa afirmação no sentido de que os AVA não sejam tidos como "vilões" - quando os participantes sentem dificuldades para acessá-los -, pois a intenção de sua construção é proporcionar um espaço dinâmico de aprendizagem e, por isto, no momento inicial do curso, a atenção do tutor deve se voltar mais para a orientação da navegação pelo ambiente do curso.

\section{Referências}

BOUfleURER, J. P. Pedagogia da ação comunicativa: uma leitura de Habermas. 3. ed. Ijuí: Editora Unijuí, 2001.

BRASIL. Ministério da Educação. Secretaria de Educação a Distância. Plano Básico do Programa de Formação Continuada Mídias na Educação. Brasília: MEC/ SEED, 2005. Disponível em: <http://portal.mec. gov.br/seed/arquivos/midias/projetobasico. pdf>. Acesso em: 7 jan. 2011. 
Ministério da Educação. Secretaria de Educação a Distância. Anuário Brasileiro Estatístico de Educação Aberta e a Distância - AbraEAD. Associação Brasileira de Educação a Distância - ABED. São Paulo: Instituto Monitor, 2008.

. Ministério da Educação. Secretaria de Educação a Distância. CensoEAD.BR. Relatório Analítico da Aprendizagem a Distância no Brasil. Associação Brasileira de Educação a Distância - ABED (Org.). São Paulo: Pearson Education do Brasil, 2010.

. Ministério da Educação. Sistema de gestão questionário de avaliação - SGQA. Disponível em: <http://sgqaadm.mec.gov. br/>. Acesso: 2 mar. 2010.

FREIRE, P. Pedagogia da autonomia: saberes necessários à prática educativa. Coleção Leitura. São Paulo, SP: Editora Paz e Terra, 2010.

Pedagogia do oprimido. São Paulo, SP: Paz e Terra, 2010.

HABERMAS, J. Teoria de la acción comunicativa. Madrid: Taurus, 1987. v. 1 e 2.

PALLOFF, R. M. O aluno virtual: um guia para trabalhar com estudantes on-line. Trad. FILGUEIRA, V. São Paulo, SP: Artmed, 2004.

PRETTI, O. A formação do professor na modalidade a distância: (des)construindo metanarrativas e metáforas. In: PRETTI, O (Org). Educação a distância: sobre discursos e práticas. Brasília, DF: Facinter, 2005.

RIO GRANDE DO NORTE. Universidade Federal do Rio Grande do Norte. Secretaria de Educação a distância. Disponível em: $<$ www.sedis.ufrn.br/>. Acesso em: 2 abr. 2011.
RIO GRANDE DO NORTE - Universidade do Estado do Rio Grande do Norte. Núcleo de Educação a Distância. Disponível em: <http://www.uern.br/nead/>. Acesso: 3 abr. 2010.

Enviado em: 15/09/2011

Aceito em: 20/12/2011 